\title{
Obnet: Network of semantic associations for obesity
}

\author{
Hossein Taghizad ${ }^{1 *}$, Mohammad Yeasin ${ }^{1,2}$, Tara Cherry ${ }^{3}$, Vida Abedi ${ }^{2}$ \\ From UT-KBRIN Bioinformatics Summit 2014 \\ Cadiz, KY, USA. 11-13 April 2014
}

\section{Background}

Obesity is a complex disease that causes health complications and mortality. Recently, the Centers for Disease Control (CDC) classified obesity as a disease and introduced guidelines for diagnosis. To understand complex relationships among all contributing factors, we have developed the ObNet (Network of Semantic Association for Obesity). The concepts were adopted from ARIANA $[1,2]$. The Local Latent Semantic Analysis tool [3], developed in the CVPIA lab, was used to extract network of semantic associations. Web services and visualization were developed to display the associations in a flexible network form that is easy to interact.

\section{Materials and methods}

In this pilot study, 198 Medical Subject Headings (MeSH) terms were selected as potential risk factors by a clinician that specializes in weight gain and obesity. Abstracts from the PubMed database were mined to create the semantic model. A Query-Based Sampling (QBS) process [3] was used to create balanced and "Representative Samples" for modeling the ObNet. A relevance model [1] was adopted to categorize associations in three groups: Clear Association, Established Concepts, and Current Research Topics.

\section{Results}

ObNet is a web service that provides users with the network of semantic associations for obesity, using literature data. The system can be queried with an array of keywords related to obesity to extract a customized network of associated entities. A pilot study using Obnet revealed current research topics in obesity. Three terms were identified and

\footnotetext{
* Correspondence: htghizad@memphis.edu

'College of Arts and Sciences, Bioinformatics program, University of Memphis, Memphis, TN 38152, USA

Full list of author information is available at the end of the article
}

evaluated by a field expert: dietary fat, adults, and attitude to health. Using a direct literature search, corroborating evidence was found to indicate the three identified terms were current research topics. First, Tan et al. [4] investigated the anti-metabolic disorder effects of kumquat (Fortunella margarita Swingle) fruit extract (FME) on high-fat diet-induced C57BL/6 obese mice. Second, in another study, 149 primary care physicians were surveyed and their knowledge and perceived barriers in the management of overweight and obesity were measured [5]. Finally, in a recent investigation, the impacts of neighborhood park access and quality on body mass index among adults in New York City were measured [6].

\section{Conclusions}

The ObNet is an innovative web service tool for the assessment of obesity. It has the potential to support diagnosis and uncover novel relationships with the disease. Empirical study suggests that the model is capable in finding network of concepts and current research trends for obesity related keywords. Future direction of the study will improve the visualization module, and develop a mobile application.

\begin{abstract}
Acknowledgements
This work was supported by the Electrical and Computer Engineering Department and Bioinformatics program at the University of Memphis as well as by NSF grants NSF-IIS-0746790. Any opinions, findings, and conclusions or recommendations expressed in this material are those of the authors and do not necessarily reflect the views of the funding institution.
\end{abstract}

\section{Authors' details}

College of Arts and Sciences, Bioinformatics program, University of Memphis, Memphis, TN 38152, USA. ${ }^{2}$ Depatrment of Electrical and Computer Engineering, University of Memphis, Memphis, TN 38152, USA. ${ }^{3}$ Department of Graduate Health Science, University of Tennessee Health Sciences Center, Memphis, TN 38163, USA.

Published: 29 September 2014 


\section{References}

1. Abedi $V$, Zand $R$, Yeasin M, Faisal FE: An automated framework for hypotheses generation using literature. BioData Min 2012, 5(1):13.

2. Abedi V, Yeasin M, Zand R: ARIANA: Adaptive robust and integrative analysis for finding novel associations. Proceedings of the 2014 International Conference on Advances in Big Data Analytics: 21-24 July 2014; Las Vegas 2014

3. Muthukuri K: Query based sampling and local semantic analysis to model network association between drugs and diseases. MS thesis The University of Memphis, Bioinformatics Program; 2013.

4. Tan S, Li M, Ding X, Fan S, Guo L, Gu M, Zhang Y, Feng L, Jiang D, Li Y, Xi W, Huang C, Zhou Z: Effects of fortunella margarita fruit extract on metabolic disorders in high-fat diet-induced obese C57BL/6 mice. PLoS One 2014, 9(4):e93510.

5. Sebiany AM: Primary care physicians' knowledge and perceived barriers in the management of overweight and obesity. J. Family Community Med 2013, 20(3):147-152.

6. Stark JH, Neckerman K, Lovasi GS, Quinn J, Weiss CC, Bader MD, Konty K, Harris TG, Rundle A: The impact of neighborhood park access and quality on body mass index among adults in New York City. Prev Med 2014, 64:63-68.

doi:10.1186/1471-2105-15-S10-P6

Cite this article as: Taghizad et al:: Obnet: Network of semantic associations for obesity. BMC Bioinformatics 2014 15(Suppl 10):P6.

\section{Submit your next manuscript to BioMed Central} and take full advantage of:

- Convenient online submission

- Thorough peer review

- No space constraints or color figure charges

- Immediate publication on acceptance

- Inclusion in PubMed, CAS, Scopus and Google Scholar

- Research which is freely available for redistribution

Submit your manuscript at www.biomedcentral.com/submit
Ciomed Central 